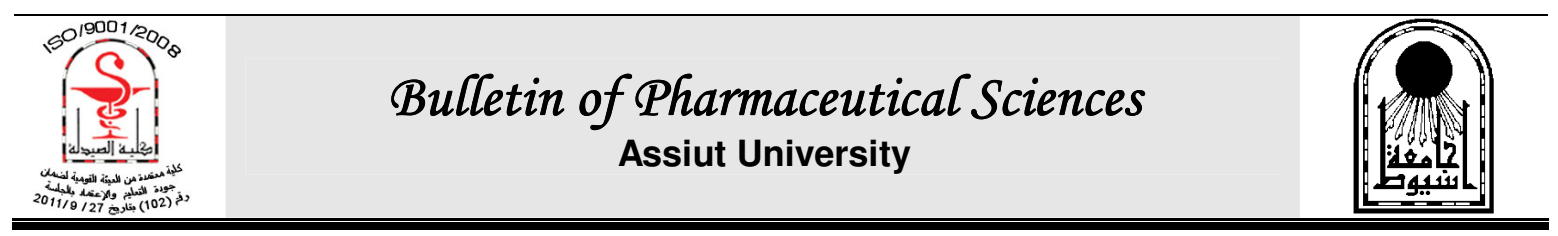

\title{
FORMULATION AND EVALUATION OF BUCCOADHESIVE SUSTAINED-RELEASE DISCS OF GLIPIZIDE
}

\author{
Ahmed E. Aboutaleb, Aly A. Abdel-Rahman, Sayed Hassan Khedr and Gamal S. Elattar \\ Department of Industrial Pharmacy, Faculty of Pharmacy, Assiut University, Assiut, Egypt
}

\begin{abstract}
Glipizide is an oral hypoglycemic agent used in the treatment of type II diabetes mellitus. It is characterized by its poor aqueous solubility and delayed absorption with concomitant food intake. The objective of the present study was to enhance the absorption rate of glipizide and avoid its side effects on stomach by formulating it into buccoadhesive sustained release disc formulations. The discs were prepared by direct compression method. Hydroxypropyl methylcellulose (HPMC 15000), was used as the main hydrophilic matrix forming polymer either alone or in combinations in two ratios (3:2 \& 4:1) with various mucoadhesive polymers namely; Sodium alginate (NaAlg), Sodium carboxymethyl cellulose (SCMC), Hydroxyethyl cellulose (HEC), Hydroxypropyl cellulose (HPC) and Chitosan. The discs were evaluated for weight variation test, thickness, diameter, drug content, hardness, friability, swelling index, surface $\mathrm{pH}$, in-vitro bioadhesion, in-vitro release studies and in-vivo bioavailability studies. Invitro release studies demonstrated that formulation F8 which contains HPMC / SCMC (40\%: $10 \%)$ has sustained the drug release up to 8 hrs which was considered an optimum pattern of drug release. The kinetic studies revealed that all formulations follows zero order release kinetics except F3, F4 and F11 which fitted well in first order release model. Bioavailability parameters including $C_{\max }, T_{\max }$, and $A U C_{0-24}$ of $F 8$ and the commercial oral tablets of glipizide (Minidiab ${ }^{\circledR} 5 \mathrm{mg}$ ) were compared. The selected formulation F8 produced higher $C_{\max }$ and extended $T_{\max }(P<0.05)$.
\end{abstract}

\section{INTRODUCTION}

Oral transmucosal drug delivery has been the focus of attention of many formulation scientists for several years.

Buccal mucosa appears to be better suited to the use of retentive systems, such as a mucoadhesive tablet or patch system, in that it has an expanse of smooth and relatively immobile surface for placement of such systems. These attributes make the buccal mucosa more suitable for sustained-delivery applications, delivery of less well permeating molecules, and perhaps peptide drugs ${ }^{1}$.

Harsh environmental factors that exist in oral delivery of a drug are circumvented by buccal delivery. Avoiding acid hydrolysis in the gastrointestinal (GI) tract and bypassing the first-pass effect are some of the advantages of this route $\mathrm{e}^{2 \& 3}$.
Glipizide is a second generation sulphonylurea that is commonly used in the pharmacological treatment of type 2 diabetes mellitus ${ }^{4}$. It acts by increasing the release of endogenous insulin as well as its peripheral effectiveness; but it has been associated with gastric disturbances like nausea, vomiting, heartburn, anorexia and increased appetite after oral therapy in the normal doses 5 .

Accordingly, there is a strong clinical need and market potential for a dosage form that will deliver glipizide in a controlled manner to a patient needing this therapy which in turns could circumvent the aforementioned problems associated with oral administration of glipizide, thereby resulting in a better patient compliance. For the aforementioned reasons, the study was developed to formulate sustained release buccoadhesive discs of glipizide as a

Received in 12/6/2016 \& Accepted in 11/4/2017 
promising alternative to the conventional oral tablets.

\section{MATERIALS AND METHODS}

\section{Materials}

Glipizide (GPZ) was kindly donated from Pharco Corporation, Alexandria, Egypt. Glibenclamide, Glimipride and Hydroxyethyl cellulose (HEC) was kindly donated from T3A Industrial, Assiut, Egypt. Hydroxypropyl methylcellulose 15000 (HPMC 15000) and Mannitol was supplied from El-Gomhouria Co., Cairo, Egypt. Sodium alginate (NaAlg) (general chemical \& pharmaceutical Co. Ltd, Sudbury Middlesex, England), Sodium carboxymethyl cellulose (SCMC) (El-Nile Co., for pharmaceutical and chemical industry, Egypt), Polyethylene glycol 6000 (PEG 6000) (Merck, Germany), Colloidal silicon dioxide (Aerosil 200) (Evonik GmbH, Germany), Magnesium stearate (MgSt) (El-Nasr Pharmaceutical Chemicals Co., Egypt), Sodium hydroxide (El-Gomhouria Co., Cairo, Egypt), Potassium dihydrogen phosphate (El-Nasr Pharmaceutical Chemicals, Cairo, Egypt), Agar (Chemi-search for chemi-trade \& laboratory supplies, Egypt) and Porcine stomach mucin was purchased from Sigma Aldrich Chem., Germany. Diethyl ether HPLC grade (Aldrich, USA), Streptozotocin (Sigma Aldrich, USA).

\section{Preparation of sustained release muco-} adhesive buccal discs of GPZ

Glipizide $5 \mathrm{mg}$ discs were prepared by the direct compression technique. All ingredients of the discs were passed through $100 \mu \mathrm{m}$ sieve, weighed using electric sensitive balance (Sartorius A200S, Germany) and mixed by trituration using a pestle and mortar to obtain uniform mixing. Powder blends weighing 200 mg each were compressed by a single punch tablet machine (Korsch-Berlin, Ek/0, Frankfurt, Germany) using flat faced $13 \mathrm{~mm}$ tablet tooling. HPMC was considered the main polymer and was used as a single polymer or in combination in certain ratios $(3: 2 \& 4: 1)$ with other polymers. Mannitol was added as a diluent to obtain the desired weight of each disc (200 mg). PEG 6000 was used as a solubility enhancer. Aerosil 200 was used as a glidant and as an anti-adherent. Magnesium stearate $(1 \% \mathrm{w} / \mathrm{w})$ was added as a lubricant. The compositions of all formulations are presented in table 1.

Table 1: Composition of the formulated buccoadhesive discs of GPZ.

\begin{tabular}{|c|c|c|c|c|c|c|c|c|c|c|c|c|}
\hline \multirow[b]{2}{*}{ Formula } & \multicolumn{11}{|c|}{ Ingredients (mg/Disc) } & \multirow[b]{2}{*}{ total } \\
\hline & GPZ & $\begin{array}{c}\text { HPMC } \\
15000\end{array}$ & SCMC & $\mathrm{NaAlg}$ & HEC & HPC & Chitosan & Mannitol & $\begin{array}{l}\text { PEG } \\
6000\end{array}$ & $\begin{array}{c}\text { Aerosil } \\
200\end{array}$ & $\mathrm{MgSt}$ & \\
\hline F1 & 5 & 60 & - & - & - & - & - & 86 & 45 & 2 & 2 & 200 \\
\hline F2 & 5 & 80 & - & - & - & - & - & 66 & 45 & 2 & 2 & 200 \\
\hline F3 & 5 & 60 & 40 & - & - & - & - & 46 & 45 & 2 & 2 & 200 \\
\hline $\mathrm{F} 4$ & 5 & 60 & - & 40 & - & - & - & 46 & 45 & 2 & 2 & 200 \\
\hline F5 & 5 & 60 & - & - & 40 & - & - & 46 & 45 & 2 & 2 & 200 \\
\hline F6 & 5 & 60 & - & - & - & 40 & - & 46 & 45 & 2 & 2 & 200 \\
\hline F7 & 5 & 60 & - & - & - & - & 40 & 46 & 45 & 2 & 2 & 200 \\
\hline F8 & 5 & 80 & 20 & - & - & - & - & 46 & 45 & 2 & 2 & 200 \\
\hline F9 & 5 & 80 & - & 20 & - & - & - & 46 & 45 & 2 & 2 & 200 \\
\hline F10 & 5 & 80 & - & - & 20 & - & - & 46 & 45 & 2 & 2 & 200 \\
\hline F11 & 5 & 80 & - & - & - & 20 & - & 46 & 45 & 2 & 2 & 200 \\
\hline F12 & 5 & 80 & - & - & - & - & 20 & 46 & 45 & 2 & 2 & 200 \\
\hline
\end{tabular}


Physical evaluation of glipizide buccoadhesive disc formulations

Uniformity of weight (B.P. 2009) ${ }^{6}$

For determination of tablet weight variation, twenty discs were individually weighed. The average weight was determined and the standard deviation was calculated.

\section{Disc thickness and diameter}

For each formulation, 5 discs were selected and their thickness and diameter was determined using DR. Schleuniger Tablet tester (Model 6D, Pharmatron, Incorporated, USA).

\section{Disc hardness}

For each formulation, 5 discs were selected and examined using DR. Schleuniger Tablet tester (Model 6D, Pharmatron, Incorporated, USA).

\section{Disc friability}

The percentage weight loss was calculated using the following equation:

$$
\% \mathrm{~F}=\frac{\left(w_{\text {initial }}\right)-\left(w_{\text {final }}\right)}{\left(w_{\text {initial }}\right)} \times 100
$$

Where $\mathrm{W}_{\text {initial }}$ is the intial weight of discs and $\mathrm{W}_{\text {final }}$ is the weight of discs after 100 revolutions inside the tester.

\section{Uniformity of drug content}

For each formulation, one accurately weighed disc $(n=5)$ was powdered and transferred in $100 \mathrm{ml}$ volumetric flask containing $30 \mathrm{ml}$ of ethanol, the sample was sonicated in an ultrasonic bath (Retsch $\mathrm{GmbH}$, Model UR 1, Germany) for 15 mins and the volume was made up to $100 \mathrm{ml}$ by phosphate buffer $\mathrm{pH} 6.8$, then mixed and filtered through $0.45 \mu \mathrm{m}$ nylon filter. The filtered solution, after appropriate dilution with Phosphate buffer $\mathrm{pH}$ 6.8 was analyzed by UV spectroscopy at 276 $\mathrm{nm}$ using UV-visible Spectrophotometer (JENWAY-Model 6305, England). The concentrations were calculated from the calibration curve.

\section{Swelling study of mucoadhesive buccal dises using agar-gel plate method ${ }^{7}$}

The swelling behavior of all disc formulations were evaluated using the agar-gel plate method, by placing individually weighed buccal discs $(n=3)$ of each formulation on $1 \%$ (w/v) agar plates and incubated at $37^{\circ} \mathrm{C}$. The discs were removed at time intervals $0.5,1,2$, $3,4,5,6$ and $8 \mathrm{hrs}$; excess water on the surface was carefully removed using filter paper, and the swollen discs were reweighed.

The swelling index (SI) was calculated according to the following formula:

$$
\mathrm{SI}=\frac{W_{2}-W_{1}}{W_{1}} \times 100
$$

where $\mathrm{W}_{1}$ and $\mathrm{W}_{2}$ are the initial weight of buccal discs and the weight of the swollen discs at different time intervals respectively.

\section{Surface pH study of the discs}

The surface $\mathrm{pH}$ of the buccal discs was determined in order to investigate the possibility of any side effects in-vivo. As an acidic or alkaline $\mathrm{pH}$ may irritate the buccal mucosa, it was proposed to keep the surface $\mathrm{pH}$ as close to neutral as possible. The method adopted by Bottenberg et al. ${ }^{8}$ was adopted to determine the surface $\mathrm{pH}$ of the disc. A combined glass electrode was used for this purpose. The discs were allowed to swell by keeping it in contact with $1 \mathrm{ml}$ of distilled water $(\mathrm{pH} 6.5 \pm 0.05)$ for $2 \mathrm{hrs}$ at room temperature. The $\mathrm{pH}$ was identified by bringing the electrode of a $\mathrm{pH}$ meter (JENWAY-Model 3310 , England) into contact with the discs surface and allowing the surfaces to equilibrate for $1 \mathrm{~min}$.

\section{In-virto bioadhesion}

In-vitro bioadhesion of the prepared disc formulations was examined by measuring the force required to detach the formulation from a mucin disc as a model mucosal substrate using a locally assembled device (Fig. 1) which is a modification of the reported method ${ }^{9}$. The mucin discs $200 \mathrm{mg}$ each were compressed using a hydraulic press (Perkin Elmer, USA), equipped with a $13-\mathrm{mm}$ die by applying a force of $30 \mathrm{kN}$ for 30 seconds. The mucin disc was glued with cyanoacrylate adhesive on the ground surface of one of the two holders made of Plexiglas and its surface was hydrated with $30 \mu 1$ phosphate buffer $\mathrm{pH} 6.8$. The buccal disc was glued to the other holder and put in contact with each other. A preload of $20 \mathrm{~g}$ for 3 mins was applied on the upper holder after getting them together into contact to ensure the formation of adhesive bond. The whole assembly was allowed to hang on an iron stand 
with the help of an aluminum wire fastened with a hook provided on the back of the upper holder. A pre-weighed light weight polypropylene bag was attached to the hook on the back of the lower holder with aluminum wire. Water was added to the polyethylene bag through an intravenous infusion set at a rate of 2.0 drops per second until the buccal disc detached due to the heavy weight of water infused. The weight of the empty bag plus the weight of water collected in the bag expressed as weight (gram force) required for the detachment.

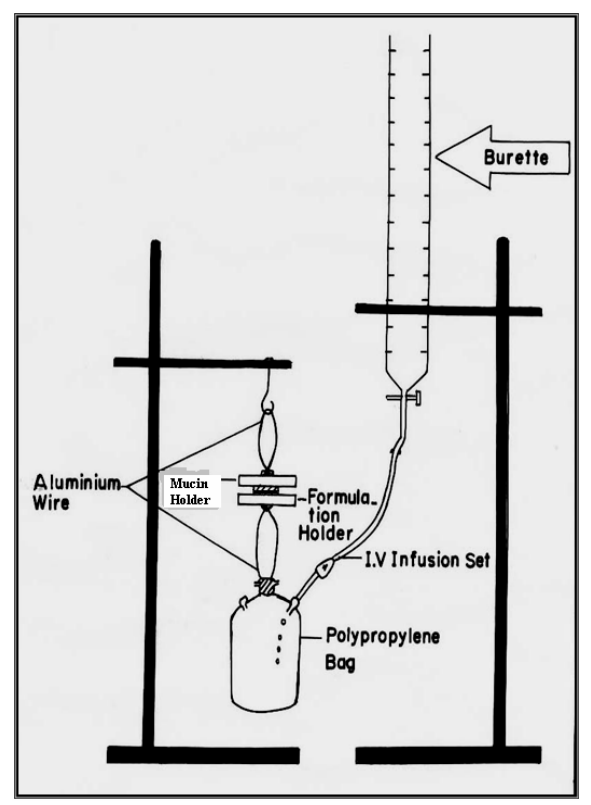

Fig. 1: Modified apparatus for discs bioadhesion test.

Each experiment was carried out in triplicate and the mean values were calculated. The detachment force was determined using the following equation:

Detachment Force $\left(\right.$ dyne $\left./ \mathrm{cm}^{2}\right)=[\mathrm{m} . \mathrm{g} / \mathrm{A}]$

Where, $m$ is the weight of empty bag and of water infused at detachment, $g$ is the acceleration due to gravity considered as 980 $\mathrm{cm} / \mathrm{s}^{2}$, and A the area of disc exposed $\left(\mathrm{cm}^{2}\right)$.

\section{In-vitro drug release from the prepared disc formulations}

The drug release from the prepared disc formulations was determined using a modified USP dissolution apparatus (Erweka DT-D6, Germany); a rotating paddle-rotating basket ${ }^{10}$.
Phosphate buffer solution of $\mathrm{pH} 6.8(500 \mathrm{ml})$ was used as the dissolution medium which was maintained at $37 \pm 0.5^{\circ} \mathrm{C}$ and stirred at a rate of $50 \mathrm{rpm}$. Aliquots $(5 \mathrm{ml}$ each) were withdrawn after 15, 30, 60, 90, 120, 180, 240, 300, 360, 420 and 480 mins, filtered through $0.45 \mu \mathrm{m}$ nylon syringe filters and analyzed spectrophotometrically at $276 \mathrm{~nm}$ for drug content. An equal amount of fresh dissolution medium, kept at the same temperature, was replaced immediately after withdrawal of the test sample. The release studies were conducted in triplicates and the mean was considered.

\section{Kinetic analysis of the drug release data}

The data of drug release from disc formulations were analyzed to determine the order of kinetic release according to the following models (zero order, first order and Higuchi diffusion).

Then, the release data were analyzed using the equation proposed by Peppas ${ }^{11}$ :

$$
\mathrm{Mt} / \mathrm{M}_{\infty}=\mathrm{Kt}^{\mathrm{n}}
$$

Where Mt / $\mathrm{M}_{\infty}$ is the fractional release of the drug at time $\mathrm{t}, \mathrm{K}$ is the release rate constant and $\mathrm{n}$ is the diffusional exponent that characterizes the type of release mechanism during the dissolution process. For non-Fickian release, the value of $\mathrm{n}$ for buccoadhesive tablets or discs (cylindrical sample) falls between 0.45 and 0.89; while in case of Fickian diffusion, $\mathrm{n}=$ 0.45 ; for zero order release (case II transport), $\mathrm{n}=0.89$ and for supercase II transport, $\mathrm{n}>0.89$.

For the determination of the exponent of $n$ the portion of the release curve where $\mathrm{Mt} / \mathrm{M}_{\infty}$ $<0.6$ should only be used ${ }^{12}$. The values of $n$ and $\mathrm{k}$ were estimated by linear regression of $\log \left(\mathrm{Mt} / \mathrm{M}_{\infty}\right)$ versus $\log \mathrm{t}$.

\section{In-vivo evaluation of adhesion behavior of the selected plain disc formulation}

The bioadhesion of the drug free discs was tested in six healthy male volunteers (aged 2232 years).

The study was conducted in accordance with the ethical principles originating from the Declaration of Helsinki and followed the ICHGCP guidelines, and was in compliance with local regulatory requirements. All subjects were completely informed concerning the pertinent details and the purpose of the study. 
A written consent form was supplied, understood and signed by each subject prior to dispensing test materials ${ }^{13}$.

The participants were instructed to press the discs against the cheek for about 30 seconds without moistening before application. Then the disc and the upper lip were moistened with saliva to prevent the sticking of the disc to the lip $^{14}$ Volunteers were allowed to drink during the study, while food intake and smoking was prohibited.

The duration of mucosal adhesion was the time required for complete wash-off of the disc.

At the end of the test period, the volunteers were asked to record:

A- The adhesion time, time of detachment or complete erosion of discs.

B- Side effects e.g. irritation (severe, moderate, slight or non-irritant), hinderance, bad taste, dry mouth, and increase in salivary flux or mucosal lesions.

\section{Accelerated stability testing of glipizide in the selected formulae of buccoadhesive discs \\ Samples from the selected disc formulation F8 were stored in amber colored glass bottles in closed desiccators containing saturated solution of sodium chloride to attain $75 \%$ relative humidity $(\mathrm{RH})$. The desiccators were kept at temperatures of 30,40 , and $50 \pm 2.0^{\circ} \mathrm{C}$ in thermostatically controlled hot air ovens (Binder, Germany) for six months. Samples from each of the selected stored formulae were withdrawn after time intervals of 1, 2, 3, and 6 months. The drug content was determined using HPLC assay method.}

\section{Chromatographic conditions for glipizide assay $^{15}$}

The drug and the internal standard were separated on C18 column, Nucleosil, C-18 column $(250 \times 4.60 \mathrm{~mm}, 7 \mu \mathrm{m})$ using High Performance Liquid Chromatographic system (HPLC, HP 1100 equipped with G1322A Degasser, G1311A Quaternary pump, G1313A ALS (autosampler), G1316A column oven, G1314A 1100 variable wavelength Detector and hp ChemStation for LC 3D Rev. A. 06.03 [509] computer software.

The mobile phase consisted of filtered and degassed mixture of methanol and water
$(80: 20 \mathrm{v} / \mathrm{v}), \mathrm{pH}$ of which was maintained at 3.5 using phosphoric acid $(85 \% \mathrm{w} / \mathrm{w})$.

The drug was eluted isocratically at a mobile phase flow rate of $1.0 \mathrm{ml} / \mathrm{min}$ and monitored with a UV detector operating at 230 $\mathrm{nm}$. Glimipride was used as internal standard.

The eluent peaks were integrated using area under curve (AUC) ratio. The column and the mobile phase were used at ambient conditions.

\section{Determination of glipizide in the stored discs}

Assay of GPZ in the stored discs was determined using HPLC method.

At the specified time intervals, three randomly selected discs were finely powdered. An accurately weighed amount of powder equivalent to $5 \mathrm{mg}$ of GPZ was transferred into $100 \mathrm{ml}$ volumetric flask and dissolved in mobile phase. The solution was subjected to vigorous shaking, and then allowed to stand for $1 \mathrm{~h}$ with intermittent sonication for complete extraction of the drug. $10 \mathrm{ml}$ of the internal standard stock solution $(0.5 \mathrm{mg} / \mathrm{ml})$ was pipetted into the volumetric flask containing the powdered formula and the volume was brought to mark with the mobile phase. The obtained solutions were filtered through 0.45 $\mu \mathrm{m}$ disk filter, degassed and $20 \mu \mathrm{l}$ were injected onto the HPLC column. GPZ concentration in each sample was determined utilizing the constructed calibration curve.

\section{Bioavailability study of glipizide from the} selected prepared buccoadhesive discs

The study was carried out to compare the pharmacokinetics of the marketed oral tablets Minidiab $^{\circledR}$ with the selected buccoadhesive discs formula (F8).

According to Paget and Barners table which related the animal dose to the daily human dose $^{16}$, dose of rabbit $(1.5 \mathrm{~kg})=$ maximum daily human dose $(15-40 \mathrm{mg}) \times 0.07$ $=(1.05-2.8 \mathrm{mg})$. So, for rabbits weighing $2 \mathrm{~kg}$; the drug doses were $(1.4-3.73 \mathrm{mg})$. For both oral and buccal administrations, the dose level of $2.5 \mathrm{mg}$ was used to ensure obtaining detectable plasma drug concentrations.

\section{Treatment of experimental animals}

The study was conducted using placebocontrolled study. Nine healthy rabbits, 
weighing 1.8-2.0 kg, were divided into three groups; each group consists of three animals.

Diabetes was induced by injecting streptozotocin $(80 \mathrm{mg} / \mathrm{kg} ; \quad$ intraperitoneal), dissolved in citrate buffer ( $3 \mathrm{mM}$; $\mathrm{pH} 4.5)$, to overnight fasted rabbits ${ }^{17}$. Seven days later, rabbits became hyperglycemic with blood glucose levels between 136-189 mg/dL. Blood glucose levels were determined using Bionime GS100 Glucometer (Bionime GmbH, Switzerland).

The first group was fasted and received oral GPZ (2.5 mg), half a tablet of (Minidiab ${ }^{\circledR} 5$ $\mathrm{mg}$ ). The second group received the selected prepared medicated buccal disc formulation (F8) which contains $2.5 \mathrm{mg}$ of the drug. The remaining group was kept as control which had received equal volume of citrate buffer without streptozotocin $^{17}$. The selected formula F8 was applied by attaching this mucoadhesive disc on the cheek pouch of rabbits. The rabbits were fasted for 24 hrs with free access to water before drug administration and anaesthetized with intraperitoneal injection of thiopental to allow adhesion of the tablets to the buccal mucosa.

\section{Blood sampling}

Blood samples of about $1 \mathrm{ml}$ were withdrawn via an indwelling catheter from the marginal ear vein into a $5 \mathrm{ml}$ screw-capped centrifuge tubes at the following time points: predose, $0.5,1,2,4,6,8,12,18$ and $24 \mathrm{hrs}$ following drug administration. The samples were centrifuged at $5000 \mathrm{rpm}$ for $15 \mathrm{mins}$ in a bench top centrifuge Z200A (Hermla Labortechnik Gm bH, Germany).

The supernatant was removed and transferred into a new screw-capped centrifuge tube. This separated plasma was stored at $20^{\circ} \mathrm{C}$ until analysis ${ }^{17 \& 18}$.

\section{Extraction and analysis of the drug from blood samples ${ }^{19}$}

Five hundred microliters of plasma or calibration standards, $50 \mu \mathrm{L}$ of internal standard solution $(10 \mathrm{mcg} / \mathrm{ml}$ glibenclamide), and $850 \mathrm{ml}$ of $0.05 \mathrm{M} \mathrm{HCl}$ were added to a glass tube. After mixing using and MS2 Minishaker (IKA ${ }^{\circledR}$ Works, INC., Wilmington, NC, USA), $5 \mathrm{ml}$ of diethyl ether was added and the mixture was stirred for 30 seconds. Each sample was centrifuged at $2500 \mathrm{rpm}$ for 10 mins. The organic layer was transferred to a new tube and evaporated to dryness under a nitrogen stream at $50^{\circ} \mathrm{C}$. The residue was reconstituted with $500 \mu \mathrm{L}$ of $50 \%$ methanol and an $80 \mu \mathrm{L}$ aliquot was injected to HPLC for analysis.

\section{Chromatographic conditions ${ }^{17}$}

The drug and the internal standard were separated on C18 column $(250 \times 4.6 \mathrm{~mm}, 5 \mu \mathrm{m})$, Ace, Advanced Chromatography Technologies Limited, Aberdeen, Scotland. The Mobile phase consisted of a mixture of acetonitrile: 2 $\mathrm{mM}$ phosphate buffer $(50: 50 \% \mathrm{v} / \mathrm{v})$, adjusted to $\mathrm{pH} 3.5$ with orthophosphoric acid. The drug was eluted isocratically at a mobile phase flow rate of $1.0 \mathrm{ml} / \mathrm{min}$ and monitored with a UV detector operating at $225 \mathrm{~nm}$. Glibenclamide was used as internal standard. The run time for the assay was $15 \mathrm{mins}$, and the retention time for the drug was $5.6 \pm 0.1$ mins and glibenclamide retention time was $12.8 \pm 0.1$ mins.

\section{RESULTS AND DISCUSSION}

Table 2 illustrates the physical properties of the prepared GPZ buccoadhesive discs. Direct compression technique produced discs of uniform weight according to B.P (2009).

The diameter and thickness of the prepared discs were also uniform with low standard deviation values (Table 2).

GPZ buccoadhesive discs prepared by direct compression technique showed acceptable hardness values ranged from 2.10 $\mathrm{kg} \pm 0.436$ to $3.83 \mathrm{~kg} \pm 0.289$ (Table 2). Discs containing sodium alginate showed the lowest hardness values. The percent weight loss (friability) of the prepared discs was also in the acceptable range $(<1 \%)$ of B.P. $2009(0.311 \%$ $-0.682 \%$ ) which indicates that all formulations are mechanically stable and have acceptable physical characteristics.

The percent of the total drug content of the prepared discs was found to be within the range from $98.67 \% \pm 2.99$ to $103.70 \% \pm 1.48$. These values indicate that all the prepared discs are uniform in drug content according to B.P (2009) requirements. 
Table 2: Physical properties of the formulated GPZ buccoadhesive discs.

\begin{tabular}{|c|c|c|c|c|c|c||}
\hline $\begin{array}{c}\text { Formul } \\
\text { a no. }\end{array}$ & $\begin{array}{c}\text { Weight }(\mathrm{mg}) \\
\mathrm{n}=20\end{array}$ & $\begin{array}{c}\text { Drug } \\
\text { content }(\%) \\
\mathrm{n}=5\end{array}$ & $\begin{array}{c}\text { Thickness } \\
(\mathrm{mm}) \\
\mathrm{n}=5\end{array}$ & $\begin{array}{c}\text { Diameter } \\
(\mathrm{mm}) \\
\mathrm{n}=5\end{array}$ & $\begin{array}{c}\text { Hardness } \\
(\mathrm{kg}) \\
\mathrm{n}=5\end{array}$ & $\begin{array}{c}\text { Friability } \\
\left(\begin{array}{c}\% \\
\mathrm{n}=5 s)\end{array}\right.\end{array}$ \\
\hline F1 & $200.47 \pm 1.01$ & $98.80 \pm 2.64$ & $1.32 \pm 0.062$ & $12.91 \pm 0.006$ & $2.13 \pm 0.321$ & 0.412 \\
\hline F2 & $200.15 \pm 1.79$ & $99.52 \pm 1.71$ & $1.30 \pm 0.017$ & $12.92 \pm 0.012$ & $2.17 \pm 0.252$ & 0.367 \\
\hline F3 & $201.42 \pm 1.69$ & $99.19 \pm 1.29$ & $1.32 \pm 0.035$ & $12.92 \pm 0.012$ & $2.73 \pm 0.907$ & 0.393 \\
\hline F4 & $200.12 \pm 2.45$ & $101.70 \pm 1.54$ & $1.29 \pm 0.006$ & $12.90 \pm 0.012$ & $3.57 \pm 1.823$ & 0.682 \\
\hline F5 & $201.38 \pm 2.36$ & $100.76 \pm 3.24$ & $1.40 \pm 0.006$ & $12.86 \pm 0.006$ & $2.13 \pm 0.451$ & 0.458 \\
\hline F6 & $202.52 \pm 1.31$ & $102.33 \pm 1.99$ & $1.34 \pm 0.053$ & $12.87 \pm 0.017$ & $3.67 \pm 1.012$ & 0.311 \\
\hline F7 & $202.05 \pm 1.70$ & $101.41 \pm 2.11$ & $1.38 \pm 0.074$ & $12.88 \pm 0.01$ & $2.17 \pm 0.503$ & 0.594 \\
\hline F8 & $201.25 \pm 1.10$ & $100.70 \pm 1.77$ & $1.34 \pm 0.006$ & $12.93 \pm 0.021$ & $2.57 \pm 0.611$ & 0.467 \\
\hline F9 & $200.38 \pm 1.42$ & $103.70 \pm 1.48$ & $1.34 \pm 0.015$ & $12.91 \pm 0.006$ & $2.10 \pm 0.436$ & 0.549 \\
\hline F10 & $202.78 \pm 1.61$ & $101.93 \pm 1.76$ & $1.39 \pm 0.058$ & $12.90 \pm 0.006$ & $2.27 \pm 0.473$ & 0.521 \\
\hline F11 & $200.37 \pm 0.92$ & $99.45 \pm 2.36$ & $1.34 \pm 0.021$ & $12.88 \pm 0.01$ & $3.83 \pm 0.289$ & 0.353 \\
\hline F12 & $200.95 \pm 1.91$ & $98.67 \pm 2.99$ & $1.34 \pm 0.01$ & $12.89 \pm 0.012$ & $2.20 \pm 0.361$ & 0.558 \\
\hline \hline
\end{tabular}

\section{Swelling studies of buccoadhesive discs}

The rate of swelling of HPMC increases with an increase in the concentration and the viscosity grade of the polymer. The swelling of matrix depends very much on the rate of water entry into the matrix. When the water uptake into matrices is enhanced with a greater amount of HPMC, the swelling of the polymer is increased.

Figure 2 shows the swelling indices of GPZ buccoadhesive discs containing HPMC $30 \%$ and $40 \%$ as a single polymer while, figures $3 \& 4$ represent the swelling indices of GPZ buccoadhesive discs containing different ratios of the mixture of each two polymers. The highest swelling index was seen in the formulation batches $\mathrm{F} 3$ which contained HPMC/SCMC (30\%:20\%) among all buccoadhesive disc formulations containing HPMC: polymer combinations. This greater tendency of water uptake might be attributed to the presence of carboxylic acid groups on the main chain of SCMC which appears to confer this polymer a higher affinity to water compared with $\mathrm{HPMC}^{20}$. Formulation F4 which contain HPMC/NaAlg (30\%:20\%) have demonstrated similar swelling behavior as F3 which could be explained by the increased porosity of discs by increasing the content of hydrophilic alginates ${ }^{21}$. HPMC / HEC formulations displayed a quite lower swelling index values as shown in figures $3 \& 4$. It was reported that HEC matrices formed a viscous gel layer immediately after coming in contact with the release medium and this gel layer was durable and resistant to erosion ${ }^{22}$. In general decreasing NaAlg, SCMC or HEC concentration resulted in decreasing the swelling of their respective formulations.

For HPMC / HPC and HPMC / Chitosan formulations, increasing HPC or Chitosan content led to decreased water uptake. The hydrosolubility of HPMC, despite its only moderate swelling properties, promote liquid entry and entrapment in the HPC network. High HPC contents without the initiating action of HPMC produce a smaller swelling effect ${ }^{23}$. On the other hand, Lehr et al.,1992 have reported that chitosan underwent minimal swelling in artificial intestinal fluid due to its poor aqueous solubility at neutral $\mathrm{pH}$ values ${ }^{24}$. 


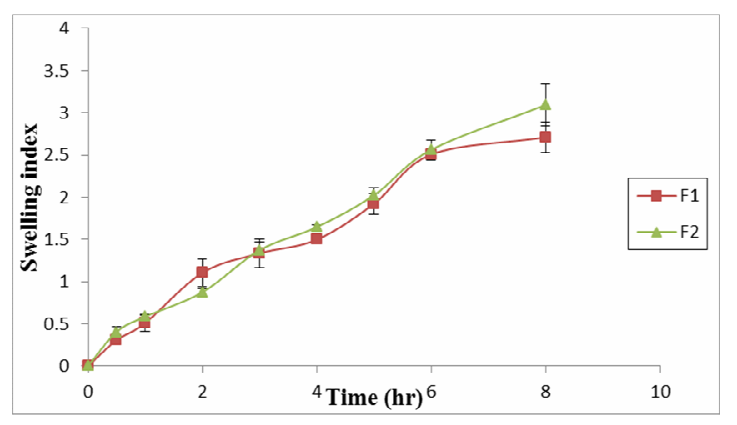

Fig. 2: Swelling indices of GPZ buccoadhesive discs containing single polymer (F1-F2) using agar-gel plate method in $\mathrm{pH} 6.8$.

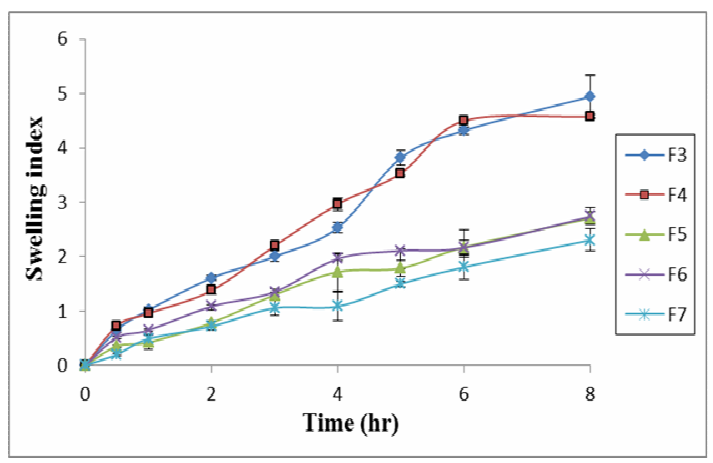

Fig. 3: Swelling indices of GPZ buccoadhesive discs (F3-F7) containing various bioadhesive polymer combinations (HPMC $30 \%$ : polymer $20 \%$ ) using agar-gel plate method in $\mathrm{pH} 6.8$.

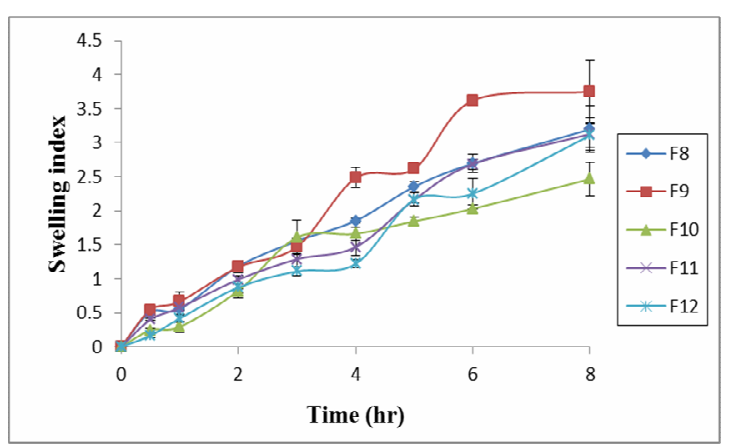

Fig. 4: Swelling indices of GPZ buccoadhesive discs (F8-F12) containing various bioadhesive polymer combinations (HPMC 40\%: polymer $10 \%$ ) using agar-gel plate method in $\mathrm{pH} 6.8$.

\section{Surface pH of the discs}

The surface $\mathrm{pH}$ of the discs was determined in order to investigate the possibility of any side effects on the buccal mucosa. As an acidic or alkaline $\mathrm{pH}$ may cause irritation to the buccal mucosa, it was attempted to keep the surface $\mathrm{pH}$ as close to neutral as possible.

The prepared buccoadhesive formulations exhibited surface $\mathrm{pH}$ values within satisfactory limits around the neutral $\mathrm{pH}(6.43 \pm 0.021$ $6.88 \pm 0.028)$. These formulations may not cause irritation to the buccal mucosa since their $\mathrm{pH}$ values lies within that of salivary $\mathrm{pH}$ (5.5$7.0)^{25}$.

\section{In-vitro bioadhesion test}

In the present study, all formulations showed good bioadhesion force ranging from $41.53 \times 10^{3}$ dyne $/ \mathrm{cm}^{2}$ for formulation F5 to $82.30 \times 10^{3}$ dyne $/ \mathrm{cm}^{2}$ for formulation $\mathrm{F} 10$. There are two factors which might be contributed to the bioadhesion behavior of all formulations a) the presence of mannitol which is reported to have good bioadhesive properties that could be related to its spatial conformation, and linear configuration, which facilitated interactions between the adhesive sites (-OH groups) and the mucus layer ${ }^{26}$ and b) the wide surface area offered for binding to the buccal mucus membranes by the large and flat discs.

It was observed that buccal disc formulation F10 which contain HPMC: HEC $40 \%: 10 \%$ has the highest bioadhesive force followed by F2 and F1 which contain HPMC $40 \%$ and HPMC $30 \%$ as a single polymer, respectively.

Figure 5 depicts an increasing trend in the bioadhesive force with the increase in the concentration of SCMC, NaAlg and HPC from $10 \%$ to $20 \%$ with subsequent decrease in HPMC concentration from $40 \%$ to $30 \%$ of the disc weight. Rapid rate of hydration of SCMC led to higher degree of swelling in a short period of time, which improved entanglement of polymer chains with the mucus. This hypothesis was confirmed with that previously reported by Lehr et al. ${ }^{24}$. With discs containing $\mathrm{NaAlg}$, the concentration of the polymer had little effect on bioadhesive properties whereas with the HPC containing formulations, the bioadhesion was increased significantly with the increasing HPC concentration in the discs.

The opposite trend was observed with HEC and Chitosan combinations with HPMC as shown in figure 5 . The weak mucoadhesive properties of Chitosan may be explained by the poor wetting properties of the polymer. The results obtained with Chitosan support previous findings about its weak and short-lasting mucoadhesion $^{24}$. 


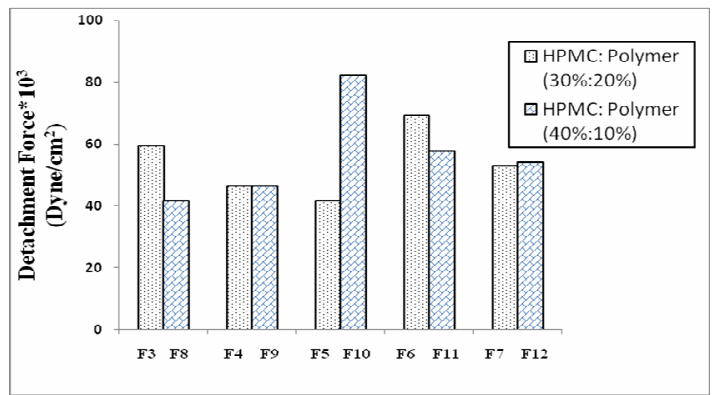

Fig. 5: In-vitro bioadhesion force of GPZ buccoadhesive discs containing certain ratios of HPMC/Polymer combinations.

\section{In-vitro drug release studies}

Increasing HPMC concentration from $30 \%$ to $40 \% \mathrm{w} / \mathrm{w}$ resulted in decreasing the percent of drug released from the prepared discs. This may be attributed to the ascending amount of the polymer which led to lengthen the diffusion path length for GPZ which could reduce the drug release ${ }^{27}$. Also, with a higher polymer concentration per unit area, the resultant gel layer would be more viscous and consequently more resistant to erosion ${ }^{28}$.

Figure 6 depicts the release profiles of GPZ from formulations (F3-F7) prepared using HPMC and various bioadhesive polymers at a ratio of $(30 \%: 20 \%)$. The release rate of GPZ from these formulations decreased in the following order:

HPMC / Chitosan $\approx$ HPMC / NaAlg > HPMC / $\mathrm{HPC} \approx \mathrm{HPMC} / \mathrm{SCMC}>\mathrm{HPMC} / \mathrm{HEC}$

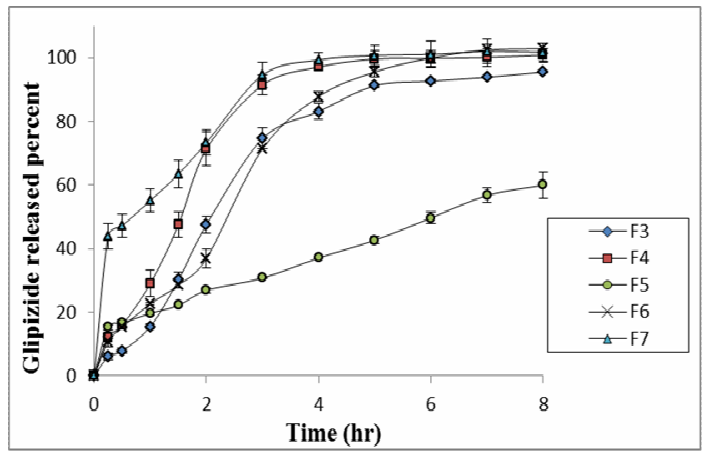

Fig. 6: Release profiles of GPZ from the prepared buccoadhesive discs (F3-F7) containing HPMC 30\%: Polymer 20\% combinations in pH 6.8 .

Figure 7 depicts the release profiles of GPZ from formulations (F8-F12) prepared using HPMC and various bioadhesive polymers at a ratio of $(40 \%: 10 \%)$. The release rate of
GPZ from these formulations decreased in the following order:

HPMC / Chitosan > HPMC / NaAlg > HPMC / SCMC > HPMC / HPC > HPMC / HEC

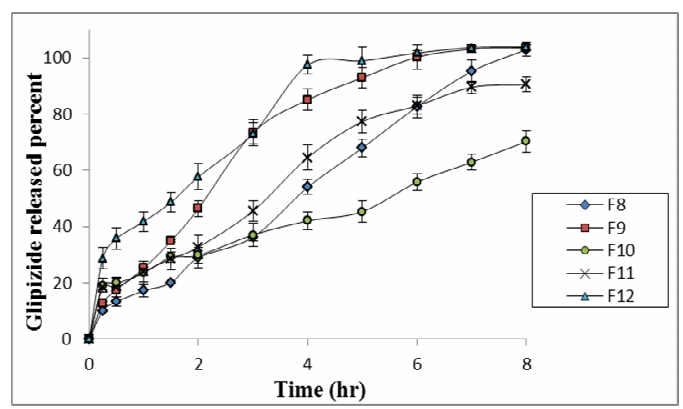

Fig. 7: Release profiles of GPZ from the prepared buccoadhesive discs (F8-F12) containing HPMC $40 \%$ : Polymer $10 \%$ combinations in pH 6.8.

Among all HPMC based formulations, only formulation F8 which contain HPMC / SCMC (40\%: 10\%) showed sustained and complete drug release, $102.95 \pm 2.53$, within the whole dissolution test period ( $8 \mathrm{hrs}$ ). On the other hand, formulations F5 and F10 which contain HPMC / HEC combinations showed marked reduction in the total release of the drug, as the percentage drug released from these formulations were $59.99 \pm 4.06$ and 70.26 \pm 3.80 respectively. Also, formulation F11 which contain HPMC: HPC (40\%: 10\%) showed incomplete drug release within $8 \mathrm{hrs}$. All other HPMC based formulations showed complete drug release in $6 \mathrm{hrs}$ and even less.

Generally, increasing the bioadhesive polymer concentration namely; SCMC, NaAlg, HPC and Chitosan from 10 to $20 \%$ relative to HPMC concentration resulted in increasing the rate of drug release. In contrast, increasing the concentration of $\mathrm{HEC}$ relative to HPMC concentration retarded the drug release from these formulations.

The rapid release of GPZ from HPMC / $\mathrm{NaAlg}$ matrices could be attributed to rapid erosion of the resultant gel layer upon increasing sodium alginate concentration. Also, SCMC swells and erodes rapidly, which explain high release rate from formulation batches containing high concentration of that polymer. Due to the erodible properties of SCMC, the discs could not maintain their matrix integrity and the erosion of polymeric matrix in the higher rate than swelling 
properties could accelerate the drug release $\mathrm{e}^{29}$. These results are in agreement with earlier workers ${ }^{30-32}$.

The fast dissolution of F7 formulation matrix was due to high percentage of Chitosan, where HPMC was not effective in maintaining matrix cohesiveness. Ionic interaction was absent between HPMC and Chitosan due to the neutral nature of the former polymer. It was reported that the rapid rate of drug dissolution from the Chitosan tablet was due to the poor gel formation ability and easy disintegration characteristics of Chitosan at neutral $\mathrm{pH}^{33}$.

Also, it has been reported that HEC matrices formed a viscous gel layer immediately after coming in contact with the release medium and this gel layer was durable and resistant to erosion ${ }^{22}$ which explains the slower rate of GPZ release from matrices containing HPMC / HEC combinations.

Kinetic analysis of the release data of glipizide from the prepared buccoadhesive discs

Table 3 shows the kinetics of release data of GPZ from discs containing different HPMC / polymer blends with certain ratios in dissolution medium of $\mathrm{pH}$ 6.8. The release of GPZ from HPMC-based buccoadhesive disc formulations followed either zero-order release mechanism especially those containing high content of HPMC or first order release mechanism.

It is generally recognized that drug release from HPMC matrices follows two mechanisms, drug diffusion through the swelling gel layer and polymer relaxation and erosion ${ }^{34}$. An increase in the quantity of the HPMC resulted in greater swelling and greater water uptake, and more polymer relaxation ${ }^{35}$. Therefore, the drug release became less diffusion governed, and its approach toward zero-order erosionaltype release.

It was found that F1 and F2 which contain ascending concentration of HPMC have $n$ values $<0.45$ which indicate a fickian drug release pattern i.e., diffusion governed drug release.

Also, It was observed that the obtained values of $\mathrm{n}$ (release exponent) of most formulations containing HPMC / SCMC, HPMC / NaAlg and HPMC / HPC combinations lies between 0.45 and 0.89 indicating that the drug release is non-fickian i.e., the mechanism of the drug release is due to polymer relaxation as well as diffusion.. On the other hand, all formulations containing HPMC / HEC or HPMC / Chitosan mixtures have $n$ values $<0.45$ indicating fickian drug release.

Table 3: Release kinetics of GPZ from the formulated buccoadhesive discs containing mixtures of HPMC and bioadhesive polymers in $\mathrm{pH} 6.8$.

\begin{tabular}{|c|c|c|c|c|c|}
\hline \multirow{2}{*}{$\begin{array}{c}\text { Formula } \\
\text { number }\end{array}$} & \multicolumn{3}{|c|}{ Correlation coefficient (r) } & \multirow{2}{*}{$\begin{array}{l}\text { Mechanism } \\
\text { of drug } \\
\text { release }\end{array}$} & \multirow{2}{*}{ K-value } \\
\hline & $\begin{array}{l}\text { Zero- } \\
\text { order }\end{array}$ & $\begin{array}{l}\text { First- } \\
\text { order }\end{array}$ & $\begin{array}{c}\text { Higuchi- } \\
\text { model }\end{array}$ & & \\
\hline $\mathrm{F} 1$ & $\underline{0.9921}$ & 0.9441 & 0.9613 & Zero-order & 0.34505 \\
\hline $\mathrm{F} 2$ & $\underline{0.9822}$ & 0.9306 & 0.9819 & Zero-order & 0.25767 \\
\hline F3 & 0.9248 & $\underline{0.9873}$ & 0.9680 & First-order & -0.007235 \\
\hline $\mathrm{F} 4$ & 0.9203 & $\underline{0.9874}$ & 0.9653 & First-order & -0.01894 \\
\hline F5 & $\underline{0.9987}$ & 0.9938 & 0.9815 & Zero-order & 0.09859 \\
\hline F6 & $\underline{0.9782}$ & 0.8858 & 0.9757 & Zero-order & 0.28918 \\
\hline F7 & $\underline{0.9882}$ & 0.9467 & 0.9819 & Zero-order & 0.26658 \\
\hline F8 & $\underline{0.9958}$ & 0.9192 & 0.9653 & Zero-order & 0.21343 \\
\hline F9 & $\underline{0.9880}$ & 0.9844 & 0.9828 & Zero-order & 0.30319 \\
\hline F10 & $\underline{0.9958}$ & 0.9804 & 0.9745 & Zero-order & 0.10710 \\
\hline F11 & 0.9844 & $\underline{0.9867}$ & 0.9793 & First-order & -0.00508 \\
\hline F12 & $\underline{0.9891}$ & 0.9393 & 0.9791 & Zero-order & 0.26127 \\
\hline
\end{tabular}

*The underlined value is the highest correlation coefficient, which indicates the operating release mechanism. $* \mathrm{k}_{0}=\left(\mathrm{mg} \cdot \mathrm{h}^{-1}\right)$. 
In-vivo bioadhesion of the selected formula (tolerance and residence time)

Good adhesion and tolerance were used as criteria for selecting the formulation to be used for clinical assessment. The prepared plain buccoadhesive discs formulation (F8) was evaluated for its tolerance and contact time on five male human volunteers.

The results revealed that the selected buccoadhesive discs had an acceptable taste and no signs of local irritation were observed. This is in agreement with many earlier workers $^{30 \& 36 \& 37}$. With respect to contact time, the discs retained readily on buccal mucosa, the mean residence time of $\mathrm{F} 8$ was more than 6.5 hrs.

\section{Accelerated stability testing of glipizide in the selected formulae of discs}

The chromatograms of GPZ standard and test preparations show a sharp peak, clearly identifiable and well-separated from the internal standard (IS) peak (Fig. 8). The retention time of GPZ and glimipride (as an internal standard) peaks were 4.2 and 5.8 mins, respectively. The chromatograms of different prepared GPZ discs show the same two peaks with the same retention time. This indicates the absence of any detectable degradation
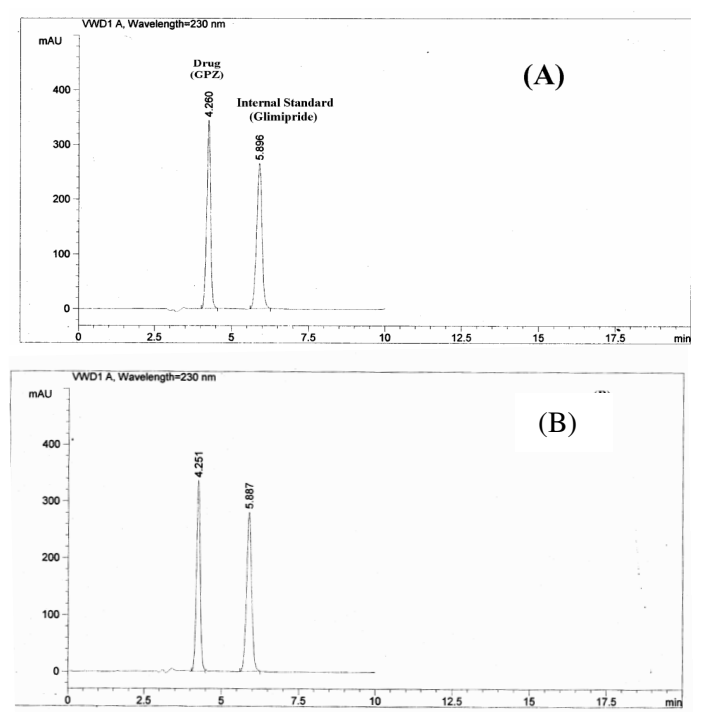

Fig. 8: HPLC chromatograms of GPZ buccoadhesive discs stored for six months at temperature of $50^{\circ} \mathrm{C}$ and $75 \%$ relative humidity:
A: Standard GPZ
B: Formula F8

products of GPZ after storage for six months at elevated temperatures and humidity indicating the chemical stability of GPZ under these storage conditions.

The chemical stability results of the selected formulation F8 demonstrated that the percentage drug remaining after storage for a period of 6 months was found to be 97.62, 97.27 and $96.83 \%$ at the three elevated temperatures 30,40 and $50^{\circ} \mathrm{C}$, respectively. Regression analysis of stability data indicated that the decomposition of the drug followed first-order kinetics.

\section{Bioavailability studies}

Figure 9 shows the mean plasma concentration-time profiles of GPZ after buccal application of formula (F8) which was selected due to its optimum drug release profile, good bioadhesion properties and acceptable physical characteristics. For comparison, the plasma concentration-time profile after oral administration of GPZ is also shown in the figure.

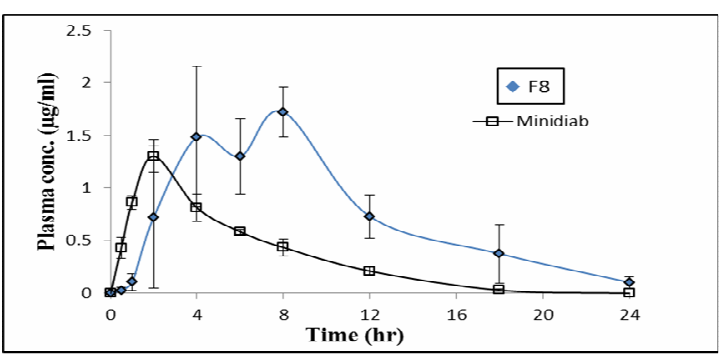

Fig. 9: Plasma concentrations of GPZ at dose level of $(2.5 \mathrm{mg})$ after administration of the commercial oral tablets $\left(\right.$ Minidiab $^{\circledR}$ ) and application of the prepared GPZ buccoadhesive discs (F8). (Error bar represents: mean \pm SD for each value).

In-vivo study demonstrates that the prepared buccal disc formula F8 achieved higher $\mathrm{C}_{\max }$ and AUC values and prolonged $\mathrm{T}_{\max }$ compared to that of the commercially available tablets (Table 4). The $\mathrm{t}_{1 / 2}$ el. was found to be $4.12 \pm 0.887 \mathrm{hrs}$ for buccal disc formula $F 8$. However, $t_{1 / 2}$ el. for the commercial oral tablets Minidiab ${ }^{\circledR}$ was found to be $3.025 \pm$ $0.348 \mathrm{hrs}$.

GPZ buccoadhesive dosage forms have $\mathrm{C}_{\max }$ values of $1.723 \pm 0.338 \mathrm{mcg} / \mathrm{ml}$ for buccal 
disc formula F8. While, $\mathrm{C}_{\max }$ value was $1.302 \pm$ $0.156 \mathrm{mcg} / \mathrm{ml}$ for Minidiab ${ }^{\circledR}$ oral tablets. There was a marked increase in the magnitude of peak plasma concentration $\left(\mathrm{C}_{\max }\right)$ after buccal administration of the prepared disc formulation F8 although it was statistically non-significant.

The $\mathrm{AUC}_{0-24 \mathrm{hr}}$ was $18.131 \pm 1.059$ $\mu \mathrm{g} . \mathrm{hr} / \mathrm{ml}$ for the selected formulation F8 which is significantly higher than the $\mathrm{AUC}_{0-24 \mathrm{hr}}$ for commercial oral tablets (Minidiab ${ }^{\circledR}$ ) which was $8.136 \pm 0.048 \mu \mathrm{g} . \mathrm{hr} / \mathrm{ml}$.

These observations clearly indicate that the bioavailability of GPZ from buccoadhesive disc is markedly increased by more than two folds of the oral bioavailability of the drug (Table 4) and so give a useful economical value by reducing the dose of the drug during the manufacturing process which in turns will be favored by patients due to avoidance of GPZ possible side effects on stomach. Also, the ease of removal of these buccoadhesive dosage forms and rapid discontinuation of therapy (i.e. prevention of further drug influx into the circulation through detachment of these dosage forms from their site of application) would be of great benefit as in case of hypoglycemia.

However, these results have revealed that these buccoadhesive formulations suffered from relatively slow rate of absorption. Thus, the incorporation of a second immediate release layer in further studies would be highly recommended.

Table 4: Pharmacokinetic parameters of GPZ following buccal application of the prepared buccoadhesive disc formula (F15) and the commercial oral tablets (Minidiab ${ }^{\circledR}$ ) to rabbits.

\begin{tabular}{|c|c|c|c|}
\hline $\begin{array}{c}\text { Pharmacokinetic } \\
\text { Parameters } \\
\end{array}$ & $\begin{array}{c}\text { Commercial } \\
\text { tablet Minidiab }^{\circledR}\end{array}$ & Disc formula F8 & $\begin{array}{l}\text { Significance of } \\
\text { the difference* }\end{array}$ \\
\hline $\mathrm{C}_{\max }(\mu \mathrm{g} / \mathrm{ml})$ & $1.302 \pm 0.156$ & $1.723 \pm 0.338$ & N.S. \\
\hline $\mathrm{T}_{\max }(\mathrm{hr})$ & 2 & 8 & S. \\
\hline $\mathrm{K}_{\mathrm{el}}\left(\mathrm{hr}^{-1}\right)$ & $0.229 \pm 0.027$ & $0.168 \pm 0.063$ & N.S. \\
\hline $\mathrm{t}^{1} / 2$ el. $(\mathrm{hr})$ & $3.025 \pm 0.348$ & $4.12 \pm 0.887$ & N.S. \\
\hline $\begin{array}{l}\mathrm{AUC}_{0-24} \mathrm{hr} \\
(\mu \mathrm{g} \cdot \mathrm{hr} / \mathrm{ml})\end{array}$ & $8.136 \pm 0.048$ & $18.131 \pm 1.059$ & S. \\
\hline $\begin{array}{c}\mathrm{AUC}_{(0-\infty)} \\
(\mu \mathrm{g} \cdot \mathrm{hr} / \mathrm{ml})\end{array}$ & $8.136 \pm 0.048$ & $18.746 \pm 0.951$ & S. \\
\hline $\begin{array}{l}\text { AUMC }_{0-24 h r} \\
\left(\mu \mathrm{g} \cdot \mathrm{hr}^{2} / \mathrm{ml}\right)\end{array}$ & $44.322 \pm 3.99$ & $\begin{array}{c}162.861 \pm \\
27.593 \\
\end{array}$ & S. \\
\hline $\begin{array}{l}\operatorname{AUMC}_{(0-\infty)} \\
\left(\mu \mathrm{g} \cdot \mathrm{hr}^{2} / \mathrm{ml}\right)\end{array}$ & $44.322 \pm 3.99$ & $181.264 \pm 34.34$ & S. \\
\hline MRT(hr) & $5.447 \pm 0.450$ & $9.669 \pm 2.269$ & N.S. \\
\hline $\mathrm{Cl}_{\mathrm{T}}(\mathrm{ml} / \mathrm{min})$ & $0.307 \pm 0.0017$ & $0.133 \pm 0.007$ & S. \\
\hline $\mathrm{F}_{\mathrm{R}}(\%)$ & ----- & 222.85 & ------- \\
\hline
\end{tabular}

$* \mathrm{~S} .=$ statistically significant $(\mathrm{p}<0.05)$, N.S. $=$ statistically non-significant $(\mathrm{p}>0.05)$. 


\section{REFERENCES}

1- D. Harris and J.R. Robinson, "Drug delivery via the mucous membranes of the oral cavity", J. Pharm. Sci., 81 (1), 1-10 (1992).

2- N. Salamat-Miller, M. Chittchang and T. P. Johnston, "The use of mucoadhesive polymers in buccal drug delivery", $\boldsymbol{A d \boldsymbol { d }}$. Drug Deliver. Rev., 57 (11), 1666-1691 (2005).

3- C. A. Squier and P. W. Wertz, "Structure and function of the oral mucosa and implications for drug delivery.", Drugs Pharm. Sci., 74, 1-26 (1996).

4- R. Foster and G. Plosker, "Glipizide", PharmacoEconomics, 18 (3), 289-306 (2000).

5- S. N. Davis and D. K. Granner, "Insulin, Oral Hypoglycemic Agents, and The Pharmacology of The Endocrine Pancreas: In Goodman \& Gilman's", The Pharmacological Basis of Therapeutics, J.G. Hardman, et al., Editors, 1996, NewYork, McGraw-Hill., pp. 1487-1517.

6- B. P. Commission, British Pharmacopoeia, 2009: Stationery Office

7- Harris, D. and J. R. Robinson, "Bioadhesive polymers in peptide drug delivery", Biomaterials, 11 (9), 652-658 (1990).

8- P. Bottenberg, et al., "Development and testing of bioadhesive, fluoride-containing slow-release tablets for oral use", $\boldsymbol{J}$.

Pharm. Pharmacol., 43 (7), 457-464 (1991).

9- V. Agarwal and B. Mishra, "Design, development, and biopharmaceutical properties of buccoadhesive compacts of pentazocine", Drug Dev. Ind. Pharm., 25 (6), 701-709 (1999).

10- G. K. Shiu, "Dissolution methodology: Apparatus and conditions*", Drug Inf. J., 30 (4), 1045-1054 (1996).

11- P. L. Ritger and N. A. Peppas, "A simple equation for description of solute release II. Fickian and anomalous release from swellable devices", J. Control. Release, 5 (1), 37-42 (1987).

12- P. Costa and J. M. S. Lobo, "Modeling and comparison of dissolution profiles", Eur. J. Pharm. Sci., 13 (2), 123-133 (2001).
13- F. Cilurzo, et al., "Polymethacrylate salts as new low-swellable mucoadhesive materials", J. Control. Release, 88 (1), 4353 (2003).

14- R. Khanna,, S. Agarwal and A. Ahuja, "Preparation and evaluation of bioerodible buccal tablets containing clotrimazole", Int. J. Pharm., 138 (1), 67-73 (1996).

15- N. Sultana, et al., "Simultaneous determination of glipizide and glimepride by Rp-Hplc in dosage formulations and in human serum", Med. Chem. Res., 21 (9), 2443-2448 (2012).

16- G. E. Paget and J. M. Barnes, "Toxicity Tests, In Evaluation of Drug Activities: Pharmacometrics", D. R. Laurence and A. L. Bacharach, Editors, 1964, New York: Academic Press. p. 134-166.

17- A. Abdelbary, N. El-Gendy and A. Hosny, "Microencapsulation approach for orally extended delivery of glipizide: In-vitro and in-vivo evaluation", Indian $J$. Pharm. Sci., 74 (4), 319 (2012).

18- J. M. Sankalia, M. G. Sankalia and R. C. Mashru, "Drug release and swelling kinetics of directly compressed glipizide sustained-release matrices: Establishment of level A IVIVC", J. control. release, 129 (1), 49-58 (2008).

19- J.-W. Bae, et al., "HPLC analysis of plasma glipizide and its application to pharmacokinetic study", J. Liq. Chromatogr. R. T., 32 (13), 1969-1977 (2009).

20- Y. S. Choi, et al., "Study on gelatincontaining artificial skin: I. Preparation and characteristics of novel gelatinalginate sponge", Biomaterials, 20 (5), 409-417 (1999).

21- D. S. Roy and B. D. Rohera, "Comparative evaluation of rate of hydration and matrix erosion of HEC and HPC and study of drug release from their matrices", Eur. J. Pharm. Sci., 16 (3), 193-199 (2002).

22- S. Conti, et al., "Solution calorimetry to monitor swelling and dissolution of polymers and polymer blends", Thermochim. Acta., 450 (1), 56-60 (2006).

23- J. Fabregas and N. Garcia, "In-vitro studies on buccoadhesive tablet formulations of hydrocortisone 
hemisuccinate", Drug Dev. Ind. Pharm., 21 (14), 1689-1696 (1995).

24- C. M. Lehr, et al., "In-vitro evaluation of mucoadhesive properties of chitosan and some other natural polymers", Int. J. Pharm., 78 (1), 43-48 (1992).

25- M. Ramana, C. Nagda and M. Himaja, "Design and evaluation of mucoadhesive buccal drug delivery systems containing metoprolol tartrate", Indian J. Pharm. Sci., 69 (4), 515 (2007).

26- J. Ali, et al., "Buccoadhesive erodible disk for treatment of oro-dental infections: design and characterisation", Int. J. Pharm., 238 (1), 93-103 (2002).

27- M. Chavanpatil, et al., "Development of sustained release gastroretentive drug delivery system for ofloxacin: in-vitro and in-vivo evaluation", Ibid., 304 (1), 178184 (2005).

28- P. W. S. Heng, et al., "Investigation of the influence of mean HPMC particle size and number of polymer particles on the release of aspirin from swellable hydrophilic matrix tablets", J. control. release, 76 (1), 39-49 (2001).

29- A. Mostafavi, et al., "Development of a prolonged-release gastroretentive tablet formulation of ciprofloxacin hydrochloride: Pharmacokinetic characterization in healthy human volunteers", Int. J. Pharm., 409 (1), 128136 (2011).

30- S. A. Yehia, O. N. El-Gazayerly and E. B. Basalious, "Design and in-vitro / in-vivo evaluation of novel mucoadhesive buccal discs of an antifungal drug: relationship between swelling, erosion, and drug release", Aaps Pharmscitech, 9 (4), 1207 1217 (2008).
31- G. Ìkinci, et al., "Development of a buccal bioadhesive nicotine tablet formulation for smoking cessation", Int. J. Pharm., 277 (1), 173-178 (2004).

32- S. L. Pandey, et al., "Mucoadhesive buccal tablets of domperidone: formulation evaluation and effects of process variables", Int. J. Pharm. Investig., 44 (2), 103-110 (2014).

33- G. V. Betageri, D. V. Deshmukh and R. B. Gupta, "Oral sustained-release bioadhesive tablet formulation of didanosine", Drug Dev. Ind. Pharm., 27 (2), 129-136 (2001).

34- T. D. Reynolds, et al., "Polymer erosion and drug release characterization of hydroxypropyl hethylcellulose matrices", J. Pharm. Sci., 87 (9), 1115-1123 (1998).

35- A. Adhikary and P. R. Vavia, "Bioadhesive ranitidine hydrochloride for gastroretention with controlled microenvironmental pH", Drug Dev. Ind. Pharm., 34 (8), 860-869 (2008).

36- G. Shanker, et al., "Formulation and evaluation of bioadhesive buccal drug delivery of tizanidine hydrochloride tablets", Aaps Pharmscitech, 10 (2), 530539 (2009).

37- K. N. Raju, et al., "Formulation and Invitro evaluation of buccal tablets of metoprolol tartrate", Int. J. Pharm. Pharm. Sci., 3 (2), 239-246 (2011). 


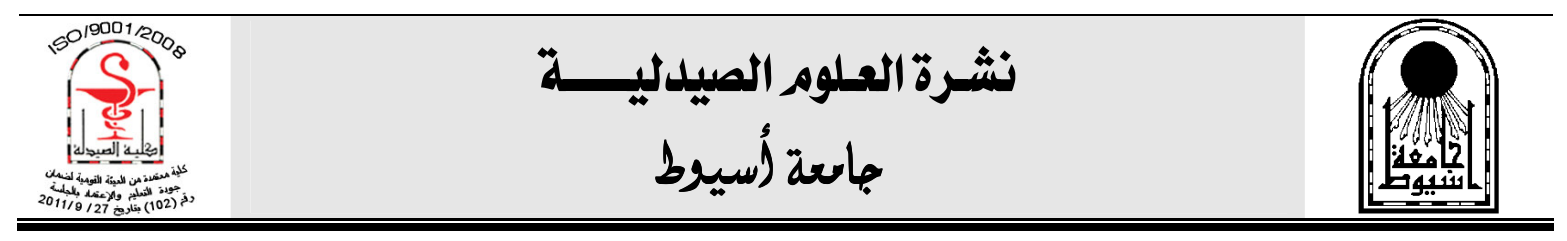

تقييم وصياغة أقر اص فمية لاصقة تحتوي على عقار الظليبيزيد

أحمد السبد ابو طالب - على عبد الظاهر عبد الرحمن -سيد حسن خضر - جمال العطار

\section{قسم الصيدله الصناعية ، كلية الصيدله ، جامعة أسيوط ، أسيوط ، مصر}

يعتبر عقار الغليبيزيد أحد العقاقير المستخدمة في خفض نسبة السكر في الدم التي نستخدم فـي

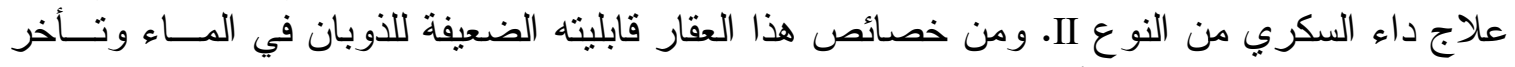

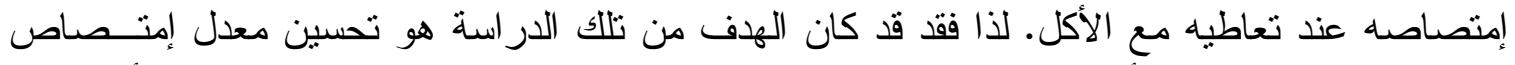

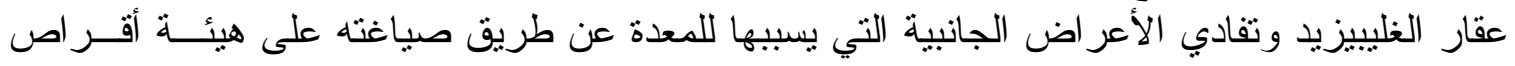

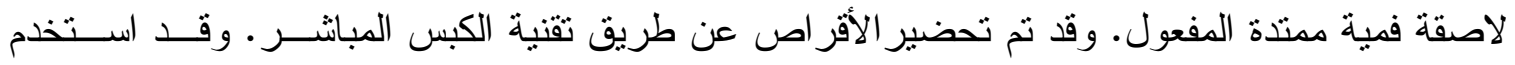

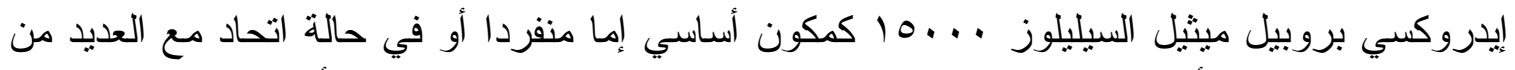

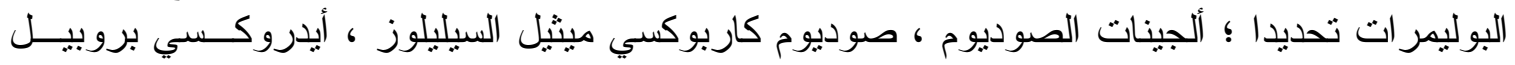

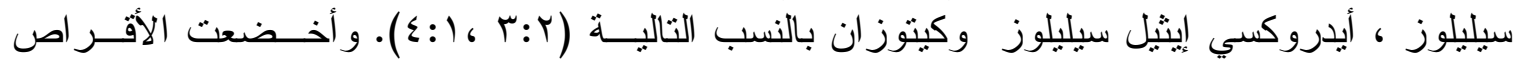

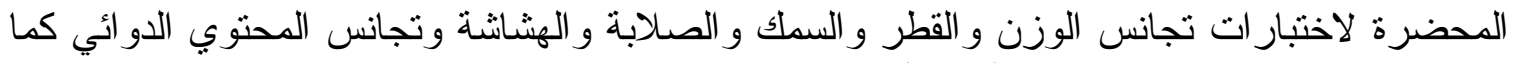

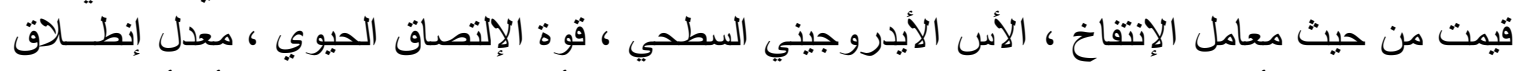

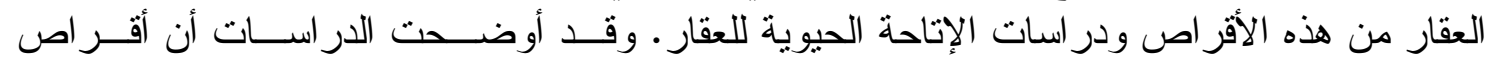

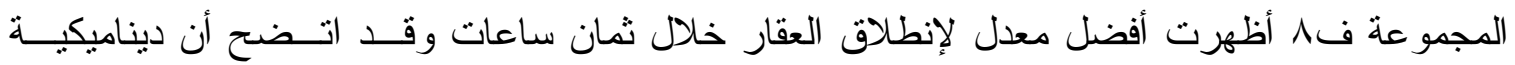

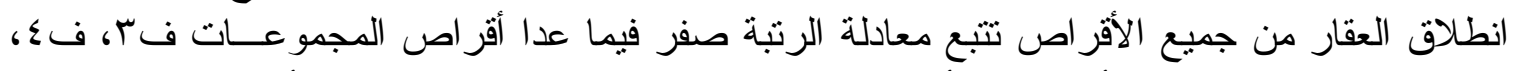

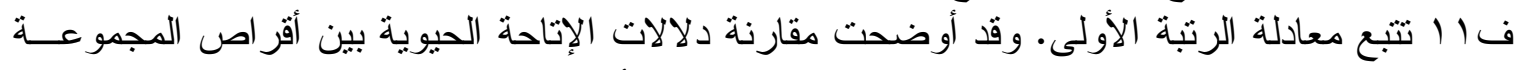

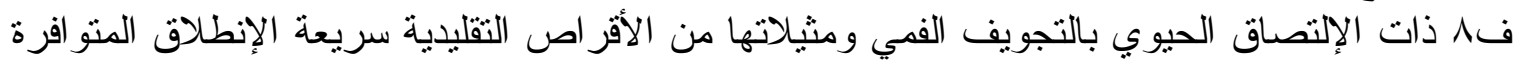

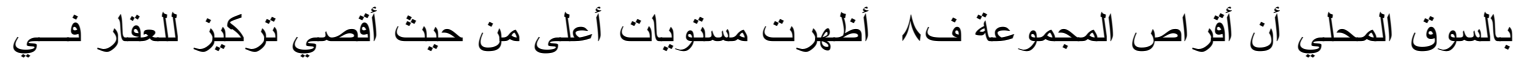

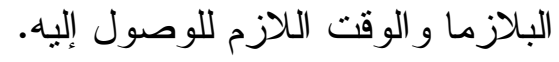

